\title{
Activating transcription factor 5 (ATF5) promotes tumorigenic capability and activates the Wnt/b-catenin pathway in bladder cancer
}

\author{
Junhao Zhou ${ }^{1 \dagger}$, Hu Tian ${ }^{1 \dagger}$, Xi Zhi ${ }^{2 \dagger}$, Zhuoyu Xiao', Taoyi Chen' ${ }^{1}$, Haoyu Yuan', Qi Chen', Mingkun Chen ${ }^{1}$, \\ Jiankun Yang', Qizhao Zhou', Kangyi Xue', Wenbin Guo', Ming Xia', Jiming Bao', Cheng Yang ', Haifeng Duan', \\ Hongyi Wang ${ }^{1}$, Zhipeng Huang ${ }^{1}$, Ting Zhu ${ }^{3^{*}}$ and Cundong Liu ${ }^{1^{*}}$ (D)
}

\begin{abstract}
Background: In bladder cancer, up to $70 \%$ of patients will relapse after resection within 5 years, in which the mechanism underlying the recurrence remains largely unclear.

Methods: Quantitative real-time PCR, western blot and immunohistochemistry were conducted. The assays of tumor sphere formation and tumor xenograft were further performed to assess the potential biological roles of ATF5 (activating transcription factor 5). Chromatin immunoprecipitation-qPCR and luciferase activity assays were carried out to explore the potential molecular mechanism. A two-tailed paired Student's $t$-test, $x^{2}$ test, Kaplan Meier and Cox regression analyses, and Spearman's rank correlation coefficients were used for statistical analyses.
\end{abstract}

Results: ATF5 is elevated in bladder urothelial cancer (BLCA) tissues, especially in recurrent BLCA, which confers a poor prognosis. Overexpressing ATF5 significantly enhanced, whereas silencing ATF5 inhibited, the capability of tumor sphere formation in bladder cancer cells. Mechanically, ATF5 could directly bind to and stimulate the promoter of DVL1 gene, resulting in activation of $\mathrm{Wnt} / \beta$-catenin pathway.

Conclusions: This study provides a novel insight into a portion of the mechanism underlying high recurrence potential of BLCA, presenting ATF5 as a prognostic factor or potential therapeutic target for preventing recurrence in BLCA.

Keywords: ATF5, Tumorigenicity, Recurrence, Wnt/ß-catenin signaling, Bladder cancer

\section{Background}

Globally, bladder cancer is the 10th most prevalent cancer type, with about 549,000 newly diagnosed patients in 2018 [1]. Unfortunately, up to $70 \%$ of these patients will

\footnotetext{
*Correspondence: zhuting90@foxmail.com; cundongliu@163.com ${ }^{\dagger} J$ unhao Zhou, Hu Tian and Xi Zhi contributed equally to this work ${ }^{1}$ Department of Urology, The Third Affiliated Hospital of Southern Medical University, Guangzhou 510630, Guangdong, People's Republic of China

${ }^{3}$ Department of Laboratory Medicine, Affiliated Cancer Hospital \& Institute of Guangzhou Medical University, Guangzhou 510095, Guangdong, People's Republic of China

Full list of author information is available at the end of the article
}

relapse upon transurethral resection of bladder cancer [2], which greatly increases the suffering of patients.

Cancer recurrence is highly associated with cancer cell drug resistance and high tumorigenic capability [3]. Moreover, these characteristics could be examined in a small cell subpopulation in bladder cancer tissue, which are called the cancer stem cells (CSC) or the tumor initiating cells (TICs) [3-5]. TICs, with high self-renewal potential, are considered to contribute to tumor heterogeneity $[6,7]$. More and more researches support the viewpoint that TICs participate in tumorigenesis and regional recurrence in bladder cancer subgroups $[4,8,9]$. 
Accordingly, targeting these TIC-like features may be an available therapy for decreasing tumor recurrence.

Ectopic stimulation of the $\mathrm{Wnt} / \beta$-catenin pathway is required for drug-resistance and self renewal in colorectal TICs, which confers a poor prognosis $[10,11]$. In bladder cancer, the $\mathrm{Wnt} / \beta$-catenin pathway takes part in epithelium stem cell maintenance [12], indicating that changes in the vital pathway may lead to the tumorigenic potential of bladder cancer. Furthermore, genetic variants in this stem cell pathway are proven to modulate the etiology of bladder cancer [13]. Therefore, investigation on the mechanisms underpinning the ectopic stimulation of $\mathrm{Wnt} / \beta$-catenin pathway in bladder cancer may provide valuable therapy target for preventing recurrence.

Activating transcription factor 5 (ATF5) belongs to the basic leucine zipper family of transcription factors. ATF5 participates in transcriptional responses of multiple cellular stressors, such as cytosolic heat shock response [14], endoplasmic reticulum unfolded protein response [15]. Several studies have reported high expression of ATF5 in undifferentiated neural progenitor cells/stem cells [16-19]. It plays a vital role in regulating cellular differentiation in various tissues, including the brain [20], liver [21], fat [22], and bone [23]. These functions that regulate the growth and differentiation in progenitor/stem cells indicate the potential role of ATF5 in the self-renewal and differentiation of TICs. Furthermore, the molecular mechanism underpinning the oncogenic role of ATF5 is largely unclear.

Herein, ATF5 was detected to be significantly upregulated in bladder urothelial carcinoma (BLCA) tissues, especially in recurrent BLCA. Ectopic ATF5 was significantly related to the clinicopathological characteristics and relapse-free survival rate of BLCA patients. Overexpressing ATF5 enhanced, whereas silencing ATF5 decreased, tumorigenic capability of BLCA in vitro and in vivo. Mechanistically, ATF5 transcriptionally upregulated $D V L 1$ expression by binding its promoter region. This study suggests that ATF5 plays a key role in tumorigenic capability of BLCA, and might be a valuable prognosis marker and potential therapeutic target for BLCA patients.

\section{Materials and methods \\ Cell culture}

Bladder cancer cells SW780 and UM-UC-3 were bought from the American Type Culture Collection (ATCC, USA) and grown in Dulbecco's modified Eagle medium (Invitrogen, Carlsbad, California, USA) with fetal bovine serum (10\%; HyClone, Logan, Utah, USA). Human lymphatic endothelial cells (HLECs) were acquired from ScienCell Research Laboratories (Carlsbad, California, USA) and maintained based on the manufacturer's directions.
Cell incubation was done at $37{ }^{\circ} \mathrm{C}$ in a $95 \%$ air and carbon dioxide (5\%) environment.

\section{Patients and collections of tissue samples}

In this study, 140 primary BLCA tissues that had been embedded in paraffin were used. Diagnosis had been histopathologically performed at The Third Affiliated Hospital of Southern Medical University and Affiliated Cancer Hospital \& Institute of Guangzhou Medical University from 2010 to 2015. Clinical as well as clinic-pathological classification and staging was evaluated based on the American Joint Committee on Cancer criteria. Clinically relevant information for the 140 study participants was listed in Table 1. Additionally, four fresh non-relapse BLCA specimens and four relapse BLCA specimens were acquired. The Clinical Trials Ethics Committee (The Third Affiliated Hospital of Southern Medical University, and Affiliated Cancer Hospital \& Institute of Guangzhou Medical University) approved this research.

Table 1 Clinicopathological characteristics of clinical samples and expression of ATF5 in 140 bladder cancer

\begin{tabular}{|c|c|c|}
\hline Characteristics & No. patients & (\%) \\
\hline \multicolumn{3}{|l|}{ Age (years) } \\
\hline$\leq 60$ & 62 & $(44.3)$ \\
\hline$>60$ & 78 & $(55.7)$ \\
\hline \multicolumn{3}{|l|}{ Gender } \\
\hline Male & 106 & $(75.7)$ \\
\hline Female & 34 & $(24.3)$ \\
\hline \multicolumn{3}{|l|}{ Grade } \\
\hline Low grade & 103 & (73.6) \\
\hline High grade & 37 & $(26.4)$ \\
\hline \multicolumn{3}{|l|}{ Stage } \\
\hline $\mathrm{Ta}, \mathrm{T} 1$ & 110 & (78.6) \\
\hline $\mathrm{T} 2-\mathrm{T} 4$ & 30 & $(21.4)$ \\
\hline \multicolumn{3}{|l|}{ Tumor size } \\
\hline$\leq 3 \mathrm{~cm}$ & 105 & (75.0) \\
\hline$>3 \mathrm{~cm}$ & 35 & $(25.0)$ \\
\hline \multicolumn{3}{|l|}{ Multiplicity } \\
\hline 1 & 97 & $(69.3)$ \\
\hline$>1$ & 43 & $(30.7)$ \\
\hline \multicolumn{3}{|l|}{ Expression of ATF5 } \\
\hline High expression & 65 & $(46.4)$ \\
\hline Low expression & 75 & (53.6) \\
\hline \multicolumn{3}{|l|}{ Recurrence } \\
\hline Yes & 38 & $(27.1)$ \\
\hline No & 102 & $(72.9)$ \\
\hline \multicolumn{3}{|l|}{ Progression } \\
\hline Yes & 26 & (18.6) \\
\hline No & 114 & (81.4) \\
\hline
\end{tabular}


RNA extraction and quantitative real-time PCR (qRT-PCR) Isolation of total RNA from cells was done using the TRIzol reagent (Invitrogen, Cat No. 15596018) as instructed by the manufacturer and used for cDNA synthesis with random primers. Normalize the expression data to $G A P D H$ gene. Expressions were calculated using the $2^{-[(\mathrm{Ct} \text { of gene })-(\mathrm{Ct} \text { of } G A P D H)]}$ method, whereby $\mathrm{Ct}$ denotes each transcripts' threshold cycles.

\section{Western blot (WB) assay}

Western blot assay was conducted as reported previously [24]. The antibodies used were: anti-ATF5 (Cat. No.HP001912, Sigma, St. Louis, MO, USA), antiactive- $\beta$-catenin (Cat. No.05-665-25UG, Pharmingen/BD Biosciences, Bedford, MA, USA), anti-DVL1 (Cat. No.ab106844, Abcam, Cambridge, MA, USA), anti-ABCG2 (Abcam, Cat. No. ab108312), anti-SOX2 (Abcam, Cat. No.ab92494) and anti-GAPDH antibody (Cat. No.T6199, Sigma-Aldrich).

\section{Immunohistochemistry (IHC)}

IHC was carried out in 140 BLCA tissues, which were detected with an anti-ATF5 antibody (Cat. No.HP001912, Sigma-Aldrich) as previously reported [24]. Immunostaining degree, separately scored by two pathologists working independently and who had been blinded to histopathological features as well as patient information, was evaluated by staining indices (SI). The SI was determined as the product of staining intensity score and tumor grade cell proportions. Grading of tumor cell proportions was as: 0 , absent positive tumor cells (PTC); $1,<2 \%$ PTC; 2 , 2-8\% PTC; 3, 8-20\% PTC; and 4, > 20\% PTC. Assessment of staining intensities was as: 1, absent staining; 2, weakly (light yellow) stained; 3, moderately (yellow-brown) stained; and 4, strongly (brown) stained. Protein expression evaluated by SI had possible scores of $0,1,2,3,4,6$, $8,9,12$ or 16 . The sample with $S I \geq 8$ was defined as highly expressed, while the sample with $\mathrm{SI}<8$ was defined as low expressed. Determination of the cut-off value was done according to the heterogeneity measure using the log rank test in accordance with overall survival.

\section{Plasmids, retroviral infection, and transfection}

Amplification of the human ATF5 gene from cDNA was done by PCR and later cloned into a pcDNA4 lentiviral vector. For silencing ATF5, cloning of 2 human ATF5targeting short hairpins RNA (shRNA) sequences into a PLKO.1 (OligoEngine, Washington, USA) was done to enable the generation of corresponding PSUPER. retro. ATF5-RNAi(s). SW780 or UM-UC-3 cells were seeded in culture plates $\left(2 \times 10^{6}\right.$ cells/p100 plate). Transfection was done using $10 \mathrm{ug}$ of designated plasmids. Cells stably
Table 2 Primers used for gene detection

\begin{tabular}{|c|c|}
\hline Gene & Sequence $\left(5^{\prime}-3^{\prime}\right)$ \\
\hline \multirow[t]{2}{*}{ ATF5 } & F:TGGCTCGTAGACTATGGGAAA \\
\hline & R: ATCAACTCGCTCAGTCATCCA \\
\hline \multirow[t]{2}{*}{ GAPDH } & F:TGTGGGCATCAATGGATTTGG \\
\hline & R: ACACCATGTATTCCGGGTCAAT \\
\hline \multirow[t]{2}{*}{ DVL1 } & F: GAGGGTGCTCACTCGGATG \\
\hline & R: GTGCCTGTCTCGTTGTCCA \\
\hline \multirow[t]{2}{*}{ NANOG } & F:TCCCGAGAAAAGATTAGTCAGCA \\
\hline & R: AGTGGGGCACCTGTTTAACTT \\
\hline \multirow[t]{2}{*}{ sox2 } & F: CTCGTGCAGTTCTACTCGTCG \\
\hline & R: AGCTCTCGGTCAGGTCCTTT \\
\hline \multirow[t]{2}{*}{$A B C G 2$} & F: CAGGTGGAGGCAAATCTTCGT \\
\hline & R: ACCCTGTTAATCCGTTCGTTTT \\
\hline \multirow[t]{2}{*}{ TCF1 } & F: CAGAGGAGAGGAACCAAGCTA \\
\hline & R: GCAACTCGGGACATAAAGCC \\
\hline \multirow[t]{2}{*}{ CCND1 } & F: GCTGCGAAGTGGAAACCATC \\
\hline & R: CCTCCTTCTGCACACATTTGAA \\
\hline \multirow[t]{2}{*}{ CD44 } & F: CTGCCGCTTTGCAGGTGTA \\
\hline & R: CATTGTGGGCAAGGTGCTATT \\
\hline \multirow[t]{2}{*}{ JUN } & F: CATTGTGGGCAAGGTGCTATT \\
\hline & R: ACAGAGCGAGTGAAAATGTGTAT \\
\hline
\end{tabular}

Table 3 The siRNA targets sequence of DVL1

\begin{tabular}{ll}
\hline Gene & Sequence $\left(5^{\prime}-\mathbf{3}^{\prime}\right)$ \\
\hline siDVL1\#1 & sense: CCAAGAUUAUCUACCACAUTT \\
siDVL1\#2 & antisense: AUGUGGUAGAUAAUCUUGGTT \\
& sense: CCAAGCUUCCCUGCUUCAATT \\
siDVL1\#3 & sense: GCAUCUACAUUGGCUCCAUTT \\
& antisense: AUGGAGCCAAUGUAGAUGCTT
\end{tabular}

expressing ATF5 or ATF5 shRNA were obtained through retroviral infection of the 293FT cells. These cells were treated for 3 days using puromycin $(3.33 \mu \mathrm{g} / \mathrm{mL})$. The promoter region of the human DVL1 gene, which had been generated via PCR-amplification from SW780 cells were cloned into NheI/BglII sites of the pGL3-basic luciferase reporter plasmids (Promega,Madison, WI, USA) in order to establish DVL1 luciferase reporters. Tables 2 and 3 shows the primers used in this study.

\section{Tumor sphere formation test}

Cells $\left(5 \times 10^{2}\right)$ were plated in 6-well ultralow cluster plates and incubated for 10 to 12 days. Incubation of tumor spheres was done in serum free DMEM/F12 (Invitrogen, Cat. No.88215) with epidermal growth factor 
(EGF, 20 ng/mL, Cat. No.37000015, PeproTech, Rocky Hill, USA), B27 (2\%, Cat. No.12587010, Invitrogen), basic fibroblast growth factor $(20 \mathrm{ng} / \mathrm{mL}$, Cat. No.10018B, bFGF, PeproTech), insulin (5ug/mL, Cat. No.100-11, PeproTech), and BSA (0.4\%, Cat. No.A1933-1G, SigmaAldrich). After 10-12 days, tumor spheres (spherical, tight, non-adherent masses that were larger than $50 \mu \mathrm{m}$ in diameter) were counted and imaged by inverse microscopy. The efficiency of sphere formation was calculated using the formulacolonies/input cells $\times 100 \%$.

\section{Luciferase reporter test}

Luciferase reporter test was conducted as described previously. In short, in triplicates, bladder cancer cells $\left(3 \times 10^{4}\right.$ cells per well $)$ were plated in 24-well plates and incubated for $24 \mathrm{~h}$. Transfection of specified plasmids as well as a pRL-TK Renilla plasmid (1.5 ng) was done using the Lipofectamine 3000 Reagent (Cat. No.L3000008, Thermo Fisher Scientific). Then, $48 \mathrm{~h}$ after transfection, the luciferase as well as Renilla signals were assessed by the Dual Luciferase Reporter Assay Kit (Cat. No.E1980, Promega) as instructed by the manufacturer.

\section{Chromatin immunoprecipitation-qPCR (ChIP-qPCR)}

The ChIP assay was carried out as previously reported [24]. In short, crosslinking was carried out using formalin (1\%) followed by cell lysis in sodium dodecyl sulfate (SDS) buffer. Then DNA fragmentation was achieved by sonication. ChIP for ATF5 was carried out with a Flag antibody (Sigma, SAB4301135). Fragments of DNA that had been eluted were detected by qPCR. The primer used for ChIP assay was shown as follow: DVL1primer 5:5'-TTGGAATGAGGCACAGGG-3', 5'-GACAGAAAA CTGCCCACC-3'.

\section{Tumor xenograft}

Male BALB/c nude mice (5-6-weekold, 16-18 g) were bought from Guangdong Experimental Animal Center (Guangdong, China) and housed in an animal holding facility on a $12 \mathrm{~h}$ dark/light cycle. Randomly, mice were allocated in to four groups ( $\mathrm{n}=6$ per group). Inguinal folds of mice were inoculated with SW780 cells $\left(1 \times 10^{6}\right.$ cells), which had been stably transfected with RNAi-vector, ATF5-RNAi\#1, ATF5 or vector, with Matrigel (to a final concentration of $25 \%$ ). An external caliper was used to assess tumor volumes, which were determined by the equation $(\mathrm{L} \times \mathrm{W} 2) / 2$. Then, $36 \mathrm{~d}$ post-inoculation, mice were euthanized by quick intraperitoneal injection of $100 \mu \mathrm{g} / \mathrm{g}$ pentobarbital sodium, and sacrificed for tumor excision.

\section{Bioinformatics analysis}

The BLCA database from The Cancer Genome Atlas (TCGA) was analyzed by Gene set enrichment analysis (GSEA, http://software.broadinstitute.org/gsea/msigdb/ index.jsp) software program (version 2.2.3).

\section{Statistical analysis}

The SPSS v.21.0 software (SPSS Inc., New York, NY, USA) was used for all analyses. Comparison of means between groups was done by a two-tailed paired Student's $t$-test. The association between ATF5 levels and clinic-pathological characteristics was calculated by $x^{2}$ test. Kaplan Meier was used for establishment of survival curves, which were compared by log-rank test. Then, survival data were calculated by univariate as well as multivariate Cox regression analyses. The bivariate correlation between variables was evaluated by Spearman's rank correlation coefficients. The $P$-value $<0.05$ was the threshold for significance.

\section{Results \\ Ectopic ATF5 expression is correlated with bladder cancer recurrence}

To investigate the significance of ATF5 in BLCA as well as its potential oncogenic mechanism, ATF5 mRNA expression was preliminary analyzed between BLCA tissues and paratumor tissues in an available BLCA data from The Cancer Genome Atlas (TCGA) database. Expression levels of the ATF5 gene in BLCA were markedly elevated than those of adjacent normal bladder tissues (Fig. 1A). Its gene expression was negatively correlated with overall survival outcomes of BLCA patients $(P=0.039$, Fig. $1 \mathrm{~B})$. Furthermore, there was a negative association between ATF5 gene expression and relapse-free survival outcomes $(P=0.013$, Fig. $1 C)$, indicating that ATF5 might be a predictor of recurrent risk in BLCA.

To assess the correlation of ATF5 expression and clinicopathological characteristics of BLCA, 140 BLCA specimens (102 non-relapse BLCA tissues and 38 recurrent BLCA tissues after treatment) were stained using a human ATF5 antibody. ATF5 expression in BLCA specimens was markedly elevated than in paratumor tissues (Fig. 1D). In addition, ATF5 expression levels in recurrent BLCA specimens were markedly elevated than those of non-relapse specimens (Fig. 1D). Statistic analysis of the 140 BLCA samples revealed that ATF5 expressions were associated with clinical grade $(P=0.034)$, stage $(P=0.014)$, tumor multiplicity $(P=0.004)$, recurrence $(P=0.022)$ as well as progression $(P=0.016)$, however, they were not correlated with gender, tumor size or age (Table 4). Importantly, Kaplan-Meier as well as logrank analyses demonstrated that ATF5 expressions were 


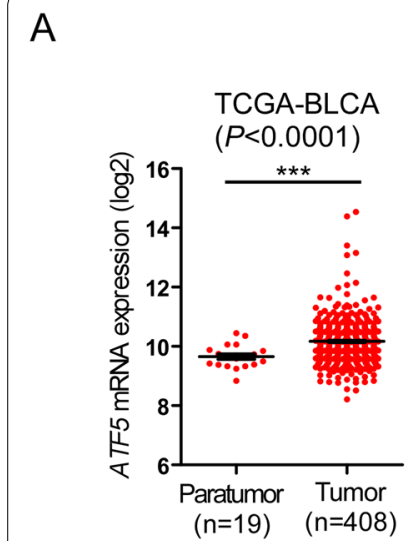

D
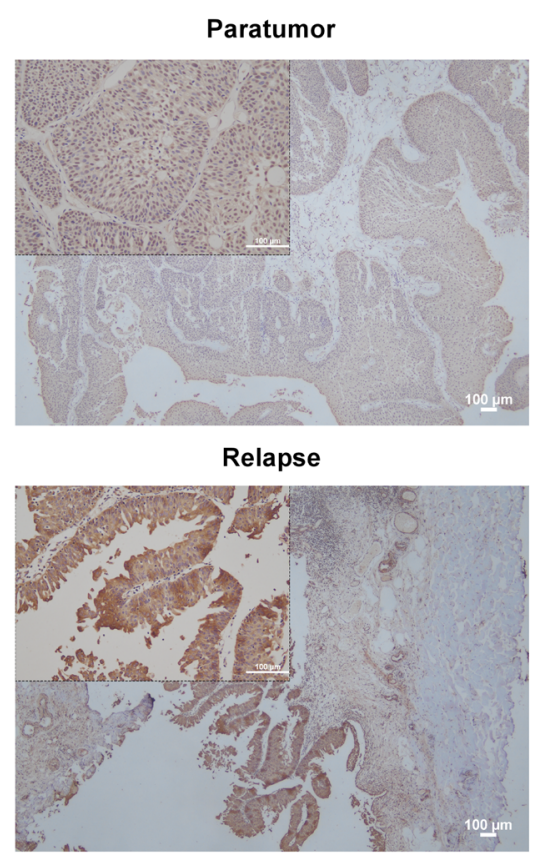
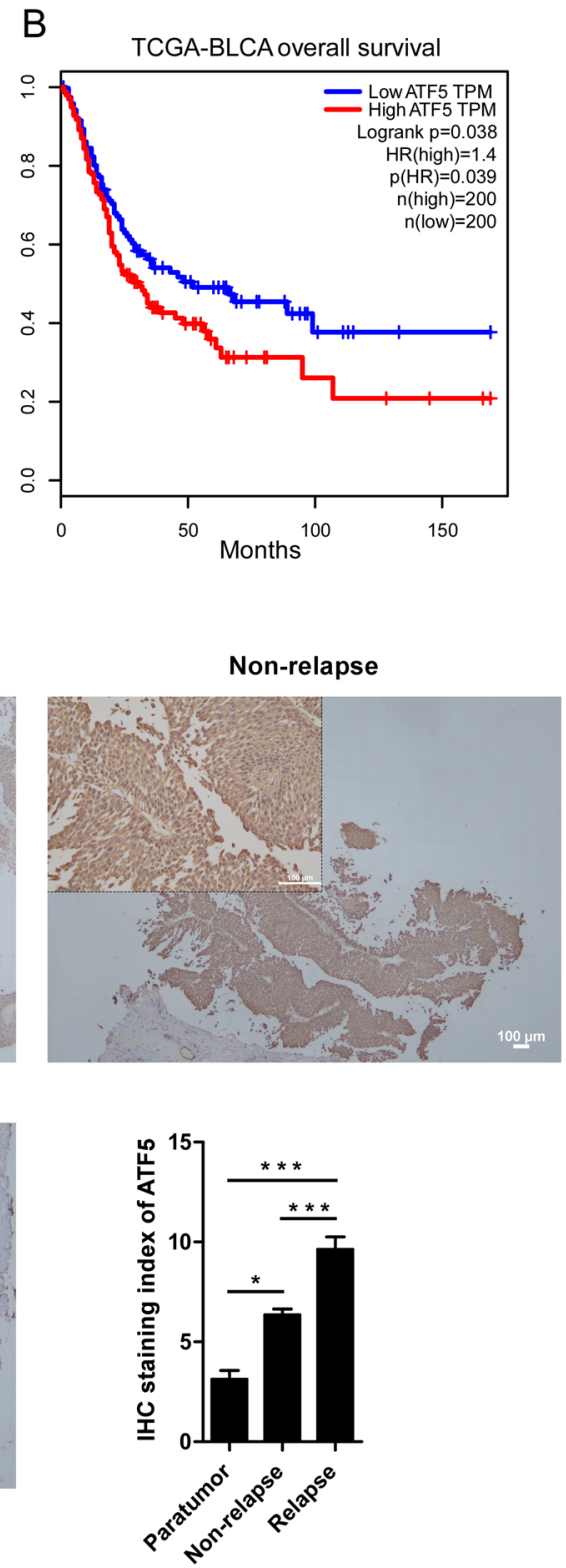

C

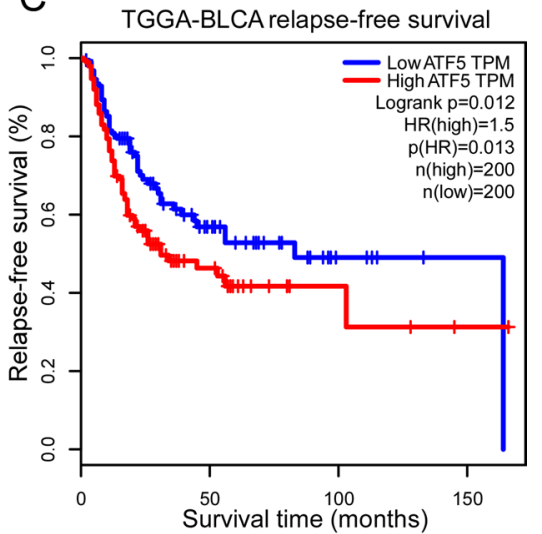

E

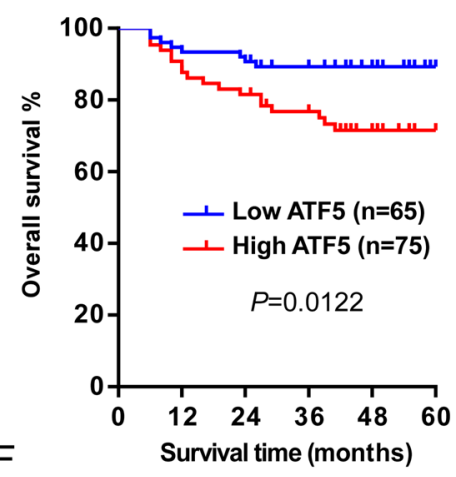

Relapse-free survival (5 years)

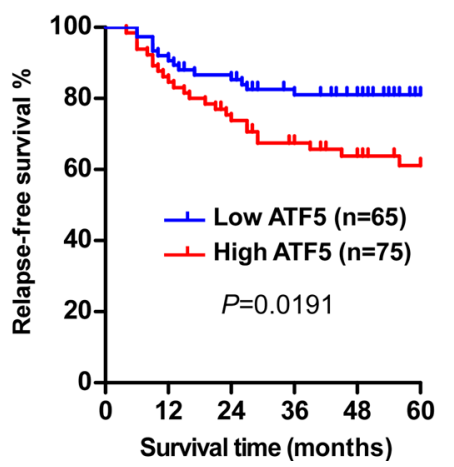

Fig. 1 Ectopic ATF5 expression is correlated with recurrence in bladder cancer. A ATF5 mRNA levels in the TCGA-BLCA dataset. B Overall survival of patients with low versus high ATF5 gene expression in TCGA-BLCA dataset. C Relapse-free survival of patients with low versus high ATF5 gene expression in TCGA-BLCA dataset. D Representative images of IHC staining in 102 non-relapse BLCA tissues and 38 BLCA tissues that recurred after therapy (left). Statistic analyses of the average staining index of ATF5 staining in paratumor bladder tissues and BLCA tissues (right). E Overall survival of BLCA patients with low versus high ATF5 expression. $\mathbf{F}$ Relapse-free survival of BLCA patients with low versus high ATF5 expression. Bars represent the mean \pm SD of three independent experiments; ${ }^{*} P<0.05,{ }^{* *} P<0.01,{ }^{* * *} P<0.001$. ATF5, activating transcription factor 5 ; TCGA, the cancer genome atlas; BLCA, bladder urothelial carcinoma; IHC, immunohistochemistry

negatively related to overall survival outcomes $(P=0.012$, Fig. 1E) and relapse-free survival outcomes $(P=0.019$, Fig. 1F). These results showed that ectopic ATF5 expression was closely related to recurrence, which predicted a poor prognosis of BLCA.
Elevated ATF5 expression in bladder cancer cells enhanced a tumor initiating cells (TIC)-like phenotype

GSEA analysis was conducted to further assess the potential biological roles of ATF5 in cancers. GSEA analysis of the public BLCA database from TCGA showed 
Table 4 Correlation between ATF5 expression and clinicopathologic charateristics of 140 bladder cancer

\begin{tabular}{|c|c|c|c|}
\hline \multirow[t]{2}{*}{ Characteristic } & \multicolumn{2}{|c|}{ ATF5 protein level } & \multirow{2}{*}{$\begin{array}{l}\text { Chi-square test } \\
P \text { value }\end{array}$} \\
\hline & High (65) & $\operatorname{Low}(75)$ & \\
\hline Age ( $>60$ versus $\leq 60$ years) & $36 / 29$ & $42 / 33$ & 0.942 \\
\hline Gender ( $\mathrm{M}$ versus F) & $46 / 19$ & $60 / 15$ & 0.238 \\
\hline Grade (low versus high) & $42 / 23$ & $61 / 14$ & $0.034^{*}$ \\
\hline Stage (Ta-1 versus T2-4) & $45 / 20$ & $65 / 10$ & $0.014^{*}$ \\
\hline $\begin{array}{l}\text { Tumor Size }(>3 \mathrm{~cm} \text { versus } \\
\leq 3 \mathrm{~cm})\end{array}$ & $21 / 44$ & $14 / 61$ & 0.079 \\
\hline $\begin{array}{l}\text { Multiplicity (single versus } \\
\text { multiple) }\end{array}$ & $37 / 28$ & $60 / 15$ & $0.004^{* *}$ \\
\hline Recurrence (Yes versus No) & $24 / 41$ & $14 / 61$ & $0.022^{*}$ \\
\hline Progression (Yes versus No) & 18/47 & $8 / 67$ & $0.016^{*}$ \\
\hline
\end{tabular}

${ }^{*} P<0.05,{ }^{* * P}<0.01$

a positive correlation between ATF5 expression and stemness signatures (Fig. 2A), which was tightly associated with cancer recurrence. Moreover, qRT-PCR and WB showed that the expression levels of stemness-associated biomarkers, such as OCT4, ABCG2 and SOX2 were markedly elevated in ATF5-overexpressed SW780 and UM-UC-3 cells, whereas reduced in ATF5-silenced bladder cancer cells (Fig. 2B-D). Subsequently, the tumor sphere formation test was carried out to investigate the role of ATF5 in self renewal of spherogenic bladder cancer cells. ATF5-knockdown cells formed fewer spheres with fewer cells relative to the control group (Fig. 2E), whereas ATF5-overexpressing cells formed more spheres with more cells (Fig. 2F). These findings indicated that ATF5 upregulation enhanced tumorigenic capability of bladder cancer cells in vitro.

To evaluate the oncogenic significance of ATF5, through the subcutaneous route, bladder cancer cells were inoculated into the inguinal area of nude mice. Tumor formation in ATF5-overexpressing SW780 cells was markedly greater, relative to the control group (Fig. 2G). Besides, ATF5-knockdown cells formed significantly smaller tumors with lower tumorigenic capability (Fig. 2G). This data demonstrated that ATF5 upregulation enhanced bladder cancer cell tumorigenic capability in vivo.

\section{ATF5 upregulation stimulates Wnt/b-catenin signaling pathway}

To investigate the mechanism underpinning ATF5mediated TIC-like phenotype in BLCA, GSEA of TCGABLCA datasets was performed to analyze the potential correlation of ATF5 expressions and genes regulated by multiple signaling signatures. ATF5 gene expression was positively related to Wnt-related and beta-catenin-related gene signatures (Fig. 3A), implying that ATF5 stimulated Wnt/ $\beta$-catenin signaling. Moreover, TOP/FOP assay demonstrated that ATF5 upregulation significantly promoted, whereas ATF5 knockdown repressed the transcriptional stimulation of TCF/LEF in the SW780 as well as UM-UC-3 cells (Fig. 3B). Consistently, WB anslysis demonstrated that ATF5 upregulation significantly elevated the active- $\beta$-catenin signals, while ATF5 attenuation decreased them (Fig. 3C). Expressions of downstream genes of the $\mathrm{Wnt} / \beta$-catenin signaling, such as CD44, TCF1, JUN and CCND1, were elevated in ATF5overexpressing cells, whereas these targets were reduced in ATF5-knockdown cells (Fig. 3D). Overall, Elevated ATF5 could stimulate $\mathrm{Wnt} / \beta$-catenin pathway.

\section{ATF5 binds, and activates the promoter of DVL1 gene}

JASPAR analysis was conducted to identify the potential downstream targets of ATF5 in the Wnt/ $\beta$-catenin pathway. $D V L 1$ gene promoters were predicted to include ATF5 binding sites (Fig. 4A). ChIP test validated that ATF5 could directly bind to DVL1 promoters (Fig. 4A and B). Moreover, ATF5 upregulation enhanced DVL1 promoter-driven luciferase activity (Fig. 4C) and DVL1 expression (Fig. 4D and E) in bladder cancer cells, while ATF5 knockdown exhibited the opposite effects (Fig. 4C-E). These data further validated that ATF5 could directly bind to and positively stimulate $D V L 1$. Subsequently, we explored whether DVL1 expression was necessary for ATF5 to promote the TIC-like phenotype of bladder cancer cells. Knockdown of DVL1 in ATF5-overexpressing cells (Fig. 4F) inhibited the expression level of stemness-related markers, including OCT4, ABCG2, and SOX2 (Fig. 4G), and expressions of downstream genes of Wnt/ $\beta$-catenin pathway (Fig. 4H). Importantly, DVL1 knockdown decreased the sphere-formation capability of ATF5-overexpressing cells (Fig. 4I). These data demonstrated that DVL1 expression was necessary for ATF5 to enhance a TIC-like phenotype of bladder cancer cell.

Altogether, this result showed that ATF5 promoted tumorigenic capability of bladder cancer cells by directly binding and promoting $D V L 1$ to stimulate the $\mathrm{Wnt} / \beta$ catenin pathway.

\section{Clinical correlation of ATF5/DVL1/beta-catenin axis in bladder cancer}

Finally, qRT-PCR and WB analyses (Fig. 5A) were performed to check if the Wnt/ATF5/DVL1 axis in bladder cancer cells is of clinical significant. There was a positive association between ATF5 protein and the DVL1 gene $\left(P=0.011, \mathrm{R}^{2}=0.734\right)$, DVL1 protein $(P=0.002$, $\left.\mathrm{R}^{2}=0.826\right)$ and the active- $\beta$-catenin expression $(P=0.008$, $\mathrm{R}^{2}=0.722$ ) in eight fresh BLCA samples (Fig. 5B-E). In summary, these results showed that ATF5 overexpression 
A
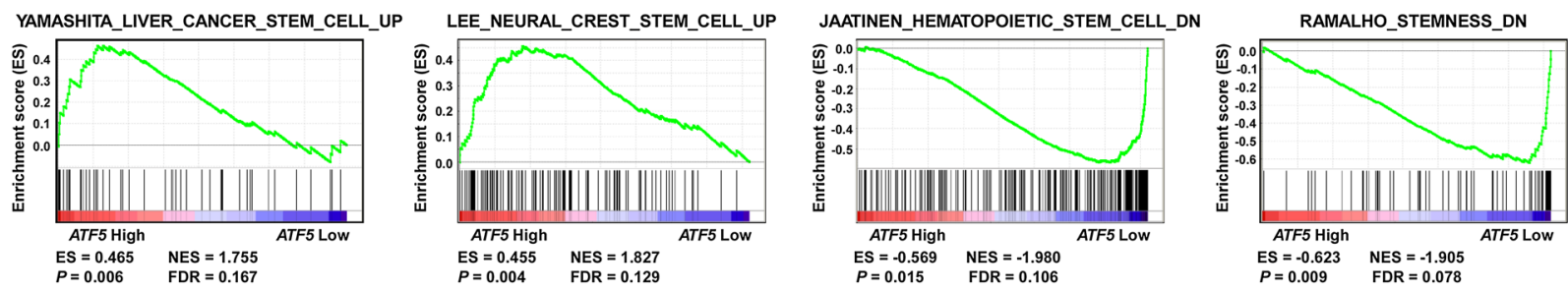

B

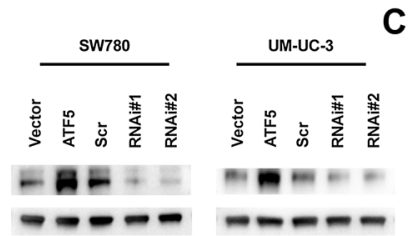

C $\square$ Vector $\square$ ATF5 $\square$ Scramble $\square$ RNAi\#1 $\square$ RNAi\#2
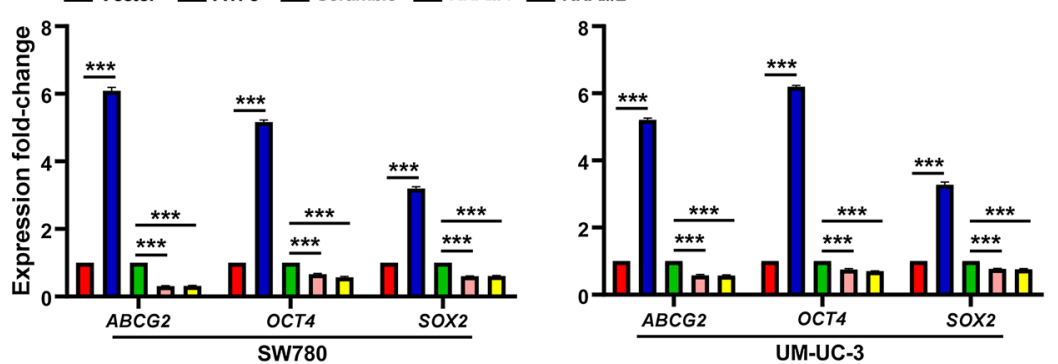

D

E

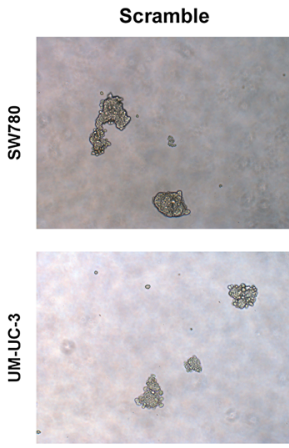

RNAi\#1

RNAi\#2

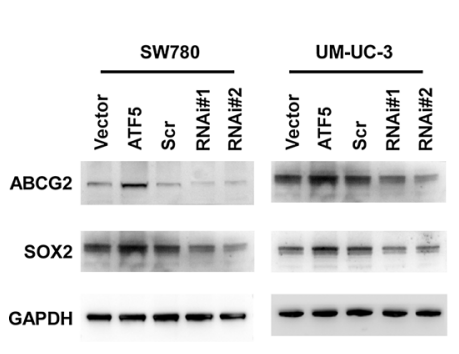

$\mathbf{F}$
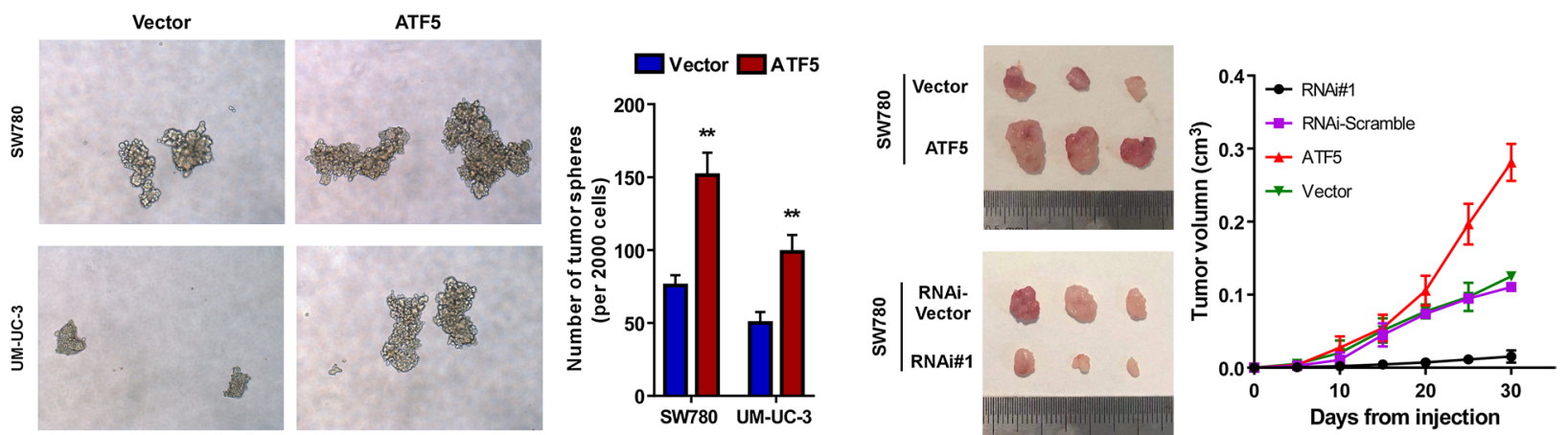

Fig. 2 ATF5 upregulation in bladder cancer cells enhances a TIC-like phenotype. A GSEA of correlations between ATF5 gene expression and stemness-related gene signatures (YAMASHITA_LIVER_CANCER_STEM_CELL_UP, LEE_NEURAL_CREST_STEM_CELL_UP, JAATINEN_HEMATOPOIETIC_ STEM_CELL_DN, RAMALHO_STEMNESS_DN). B Western blotting detection of ATF5 in the indicated ATF5-upregulation, ATF5-knockdown, or control cells. GAPDH was used as the loading control. C, D qRT-PCR (C) and WB (D) detection of stemness-related markers (ABCG2, OCT4, SOX2) in overexpressing, downregulating ATF5 or control cells. E, F Representative images and quantitative analyses of tumor sphere formation in ATF5-upregulation cells $(\mathbf{E}, \times 100)$, ATF5-knockdown cells $(\mathbf{F}, \times 100)$ or control cells. $\mathbf{G}$ Tumors formed by ATF5-overexpressing bladder cancer cells were larger than control tumors. In contrast, tumors formed by ATF5-knockdown cells were smaller than those formed by RNAi-vector cells. Representative images of tumors were displayed (left). Tumor growth curves after injection of indicated cells (right). Bars represent the mean \pm SD of three independent experiments; ${ }^{*} P<0.05,{ }^{* *} P<0.01,{ }^{* * *} P<0.001$. GSEA, gene set enrichment analysis; TIC, tumor initiating cells; qRT-PCR, quantitative real-time polymerase chain reaction; WB, western blotting 


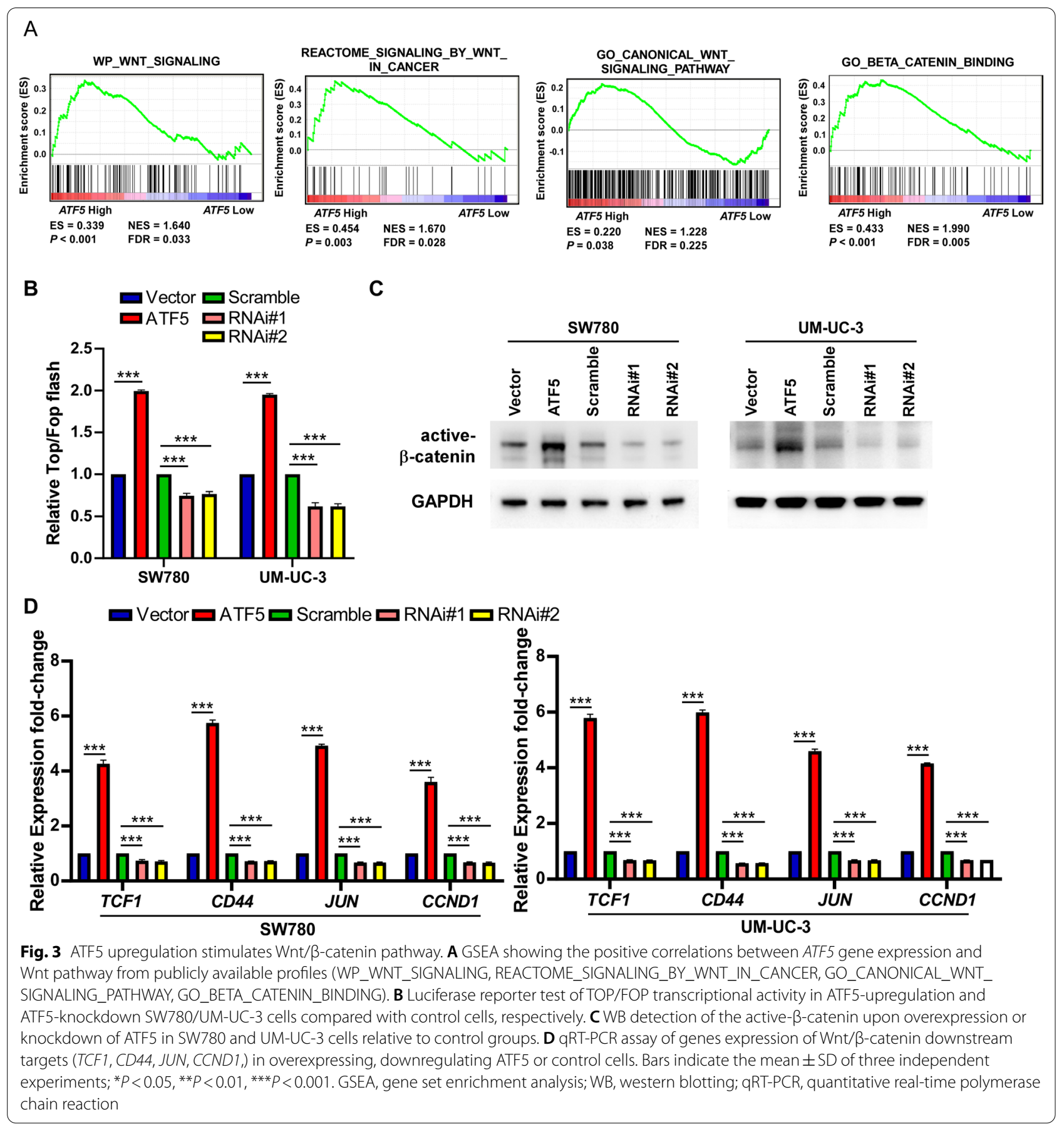

(See figure on next page.)

Fig. 4 ATF5 directly upregulates DVL1 in bladder cancer cells. A Prediction (upper panel) and validation (lower panel) of potential ATF5-target sites by JASPAR database and ChIP-qPCR assay. B ChIP-qPCR analysis showing enrichment of ATF5 at DVL1 promoter in SW780/UM-UC-3 cells upon ATF5 up-regulation or knock-down. C Luciferase reporter test of DVL1 transcriptional activity upon transfection with ATF5 plasmids and/or luciferase plasmids containing/without DVL1 promoter. D, E qRT-PCR (D) and WB (E) detection of DVL1 expression in ATF5-upregulation or ATF5-knockdown cells compared with control groups. GAPDH was used as the loading control. FWB detection of DVL1 protein in ATF5-overexpressing bladder cancer cells upon transfection with DVL1 siRNAs. G qRT-PCR detection of stemness-related markers (ABCG2, OCT4, SOX2) in ATF5-overepxressing SW780/UM-UC-3 cells upon knockdown of DVL1. H qRT-PCR assay of genes expression of Wnt/ $\beta$-catenin downstream targets (TCF1, CD44, JUN and CCND1) in ATF5-overepxressing SW780/UM-UC-3 cells transfected with DVL1 siRNAs. I Representative images (left, $\times 100$ ) and quantitative analyses (right) of tumor sphere formation in ATF5-overexpressig cells upon knockdown of DVL1. Bars represent the mean \pm SD of three independent experiments; ${ }^{*} P<0.05,{ }^{* *} P<0.01,{ }^{* * *} P<0.001$. qRT-PCR, quantitative real-time polymerase chain reaction; WB, western blotting 


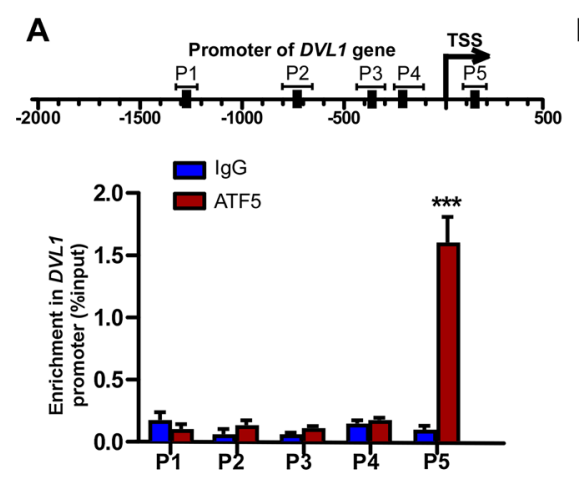

B
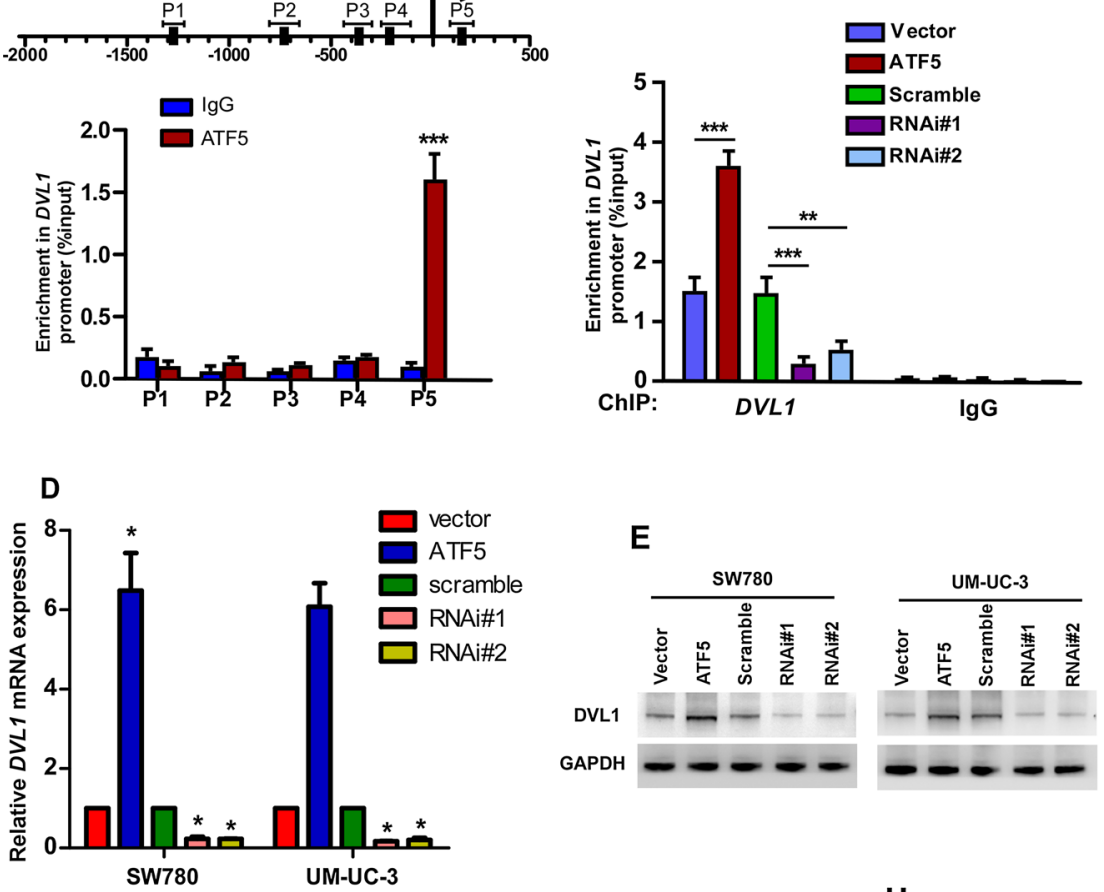

H

C

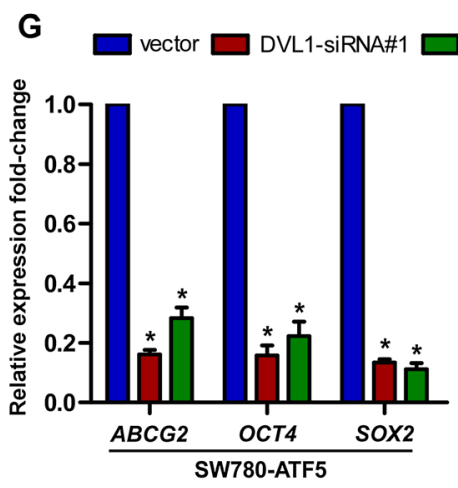

I
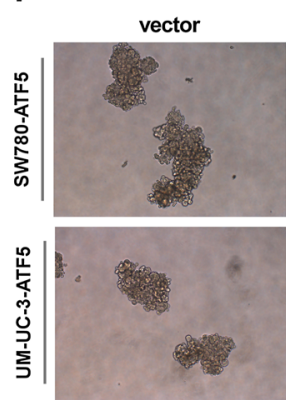
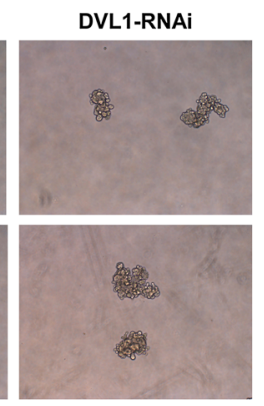
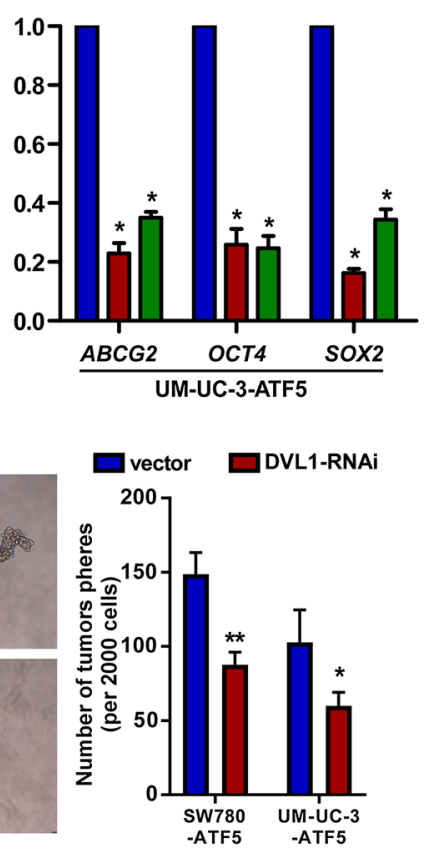

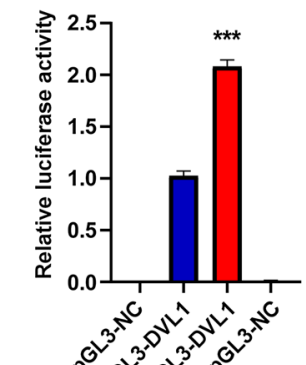

$\mathbf{F}$

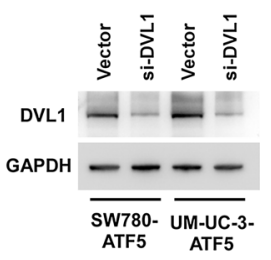

vector $\square$ DVL1-siRNA\#1 $\square$ DVL1-siRNA\#2
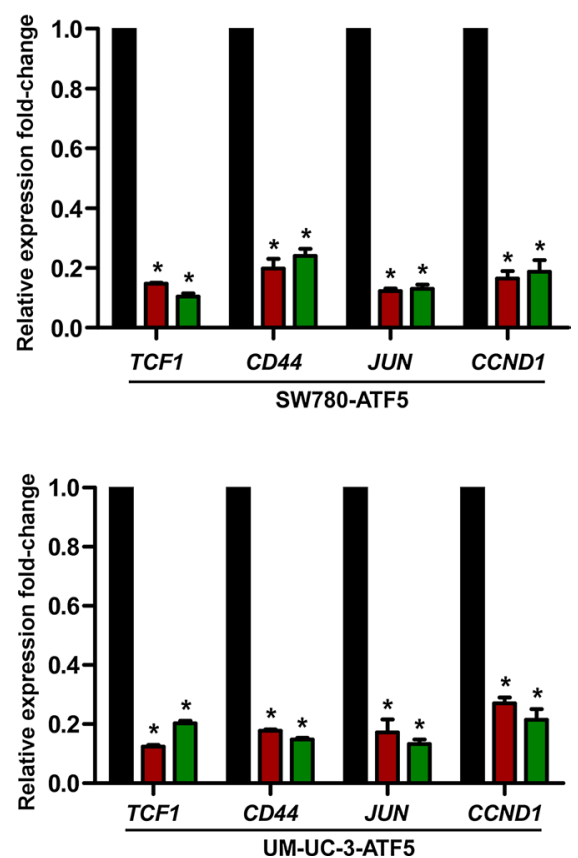

Fig. 4 (See legend on previous page.) 
A
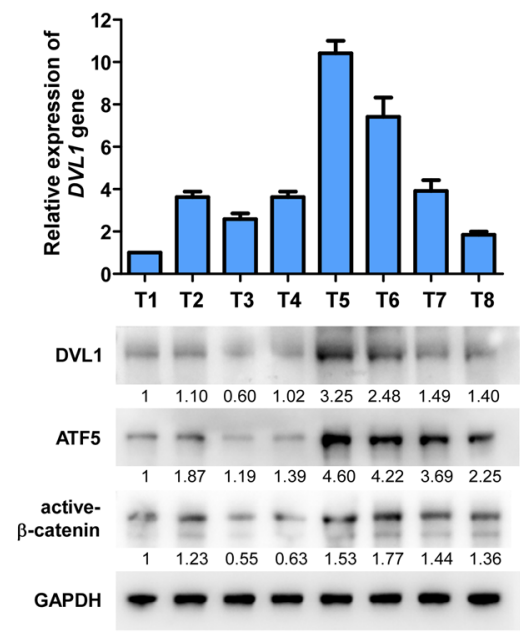

B

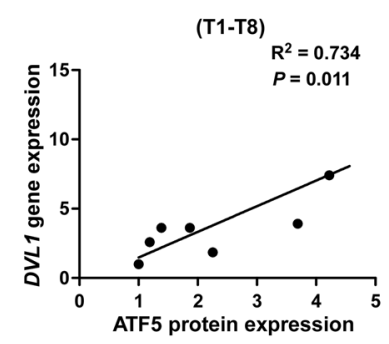

D

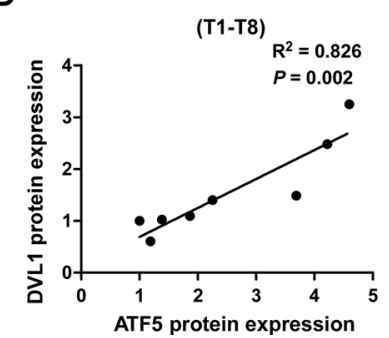

C

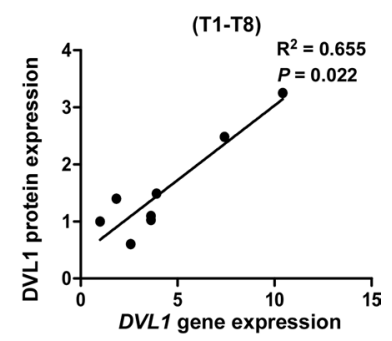

E

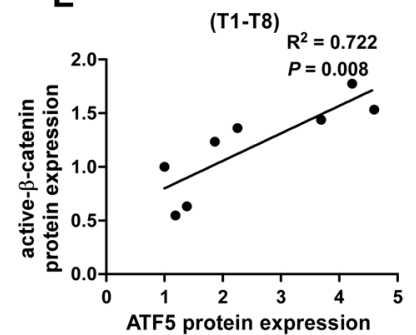

Fig. 5 ATF5 expression associated with Wnt/ $\beta$-catenin signaling stimulation in BLCA. A qRT-PCR assay of DVL1 and WB detection of DVL1, ATF5 and the active- $\beta$-catenin in eight fresh BLCA specimens; GAPDH was used as a loading control. B-E Association analyses of ATF5 expression with expression of DVL1 and the active- $\beta$-catenin in eight fresh BLCA specimens. qRT-PCR, quantitative real-time polymerase chain reaction; WB, western blotting; DVL1, dishevelled segment polarity protein 1; BLCA, bladder urothelial carcinoma

in BLCA was positively related to DVL1 expression, which in turn stimulated Wnt/ $\beta$-catenin pathway to promote tumorigenic capability of bladder cancer cell.

\section{Aberrant ATF5 amplification is involved in ATF5 overexpression in bladder cancer cells, and is correlated with poor prognostic outcomes}

In various cancers, the ATF5 locus on chromosome $19 q 13.33$ is generally amplified. The copy number variation (CNV) of ATF5 and DVL1 in TCGA-BLCA datasets were shown in Fig. $6 \mathrm{~A}$ and B. ATF5 and DVL1 mRNA levels were tightly related to the CNV (Fig. 6C and D). The amplification in CNV of ATF5 and DVL1 predicted a higher gene expression, while the deletion in CNV of AFT5 and DVL1 predicted a lower gene expression (Fig. 6E and F). However, the CNV of ATF5 was not directly associated with $D V L 1$ gene expression (Fig. 6G), indicating that ATF5 CNV does not contribute to the ectopic expression of $D V L 1$ gene. Although aberrant $\mathrm{CNV}$ of $D L V 1$ contributed to ectopic expression of $D V L 1$ gene, differences in survival outcomes between $D V L 1$ amplification or deletion patients were insignificant $(P=0.379$, Fig. 6H). Notably, bladder cancer with ATF5 amplification was found to be a predictor of worse survival outcomes than those without $A T F 5$ amplification $(P=0.014$, Fig. 6I). These results indicated that aberrant ATF5 amplification plays a role in ATF5 overexpression in bladder cancer, which conferred a poor prognosis.

\section{Discussion}

This study revealed that ATF5 facilitates the formation of tumor sphere, promotes tumorigenicity and stimulates the Wnt/ $\beta$-catenin pathway in bladder cancer. Furthermore, ATF5 was upregulated in human BLCA and elevated ATF5 was related to relapse-free survival outcomes, implying that ATF5 might be a potential prognosis marker for BLCA recurrence.

ATF5 has been demonstrated to be highly expressed in undifferentiated neural progenitor/stem cells [16-19]. It seems to repress the differentiation of bone and brain tissues [20,23], while targeted abrogation of ATF5 leads to normal differentiation in neural progenitor cells [18-20]. These studies support the potential regulation of ATF5 in the differentiation and self-renewal of TICs. In a variety of cancers, ATF5 has also been characterized to be upregulated, such as leukemia, breast cancer and gliomas [25-27]. ATF5, as a transcription factor, functions as an oncogenic role in enhancing cell survival, migration and radioresistance of cancer cells [28, 29]. Herein, ATF5 alteration significantly changed the expression of stemness-associated genes SOX2 and OCT4. SOX2 and OCT4 are transcription factors that control the 

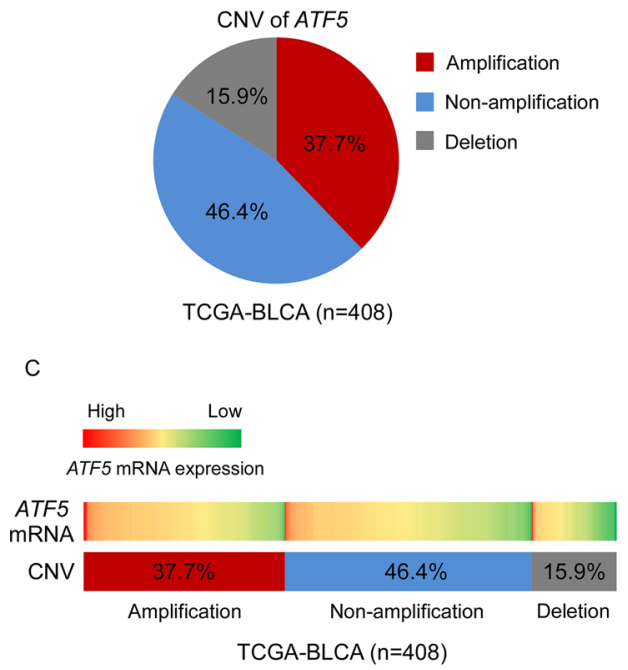

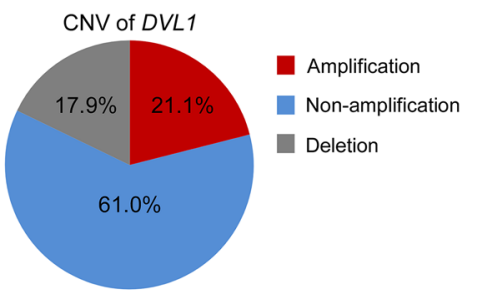

TCGA-BLCA $(n=408)$

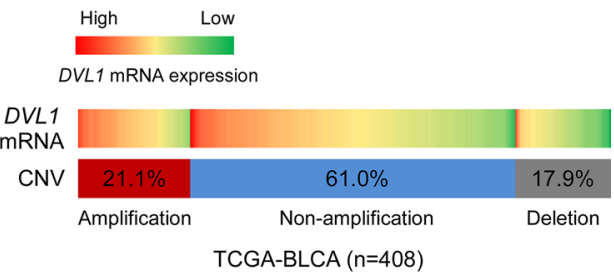

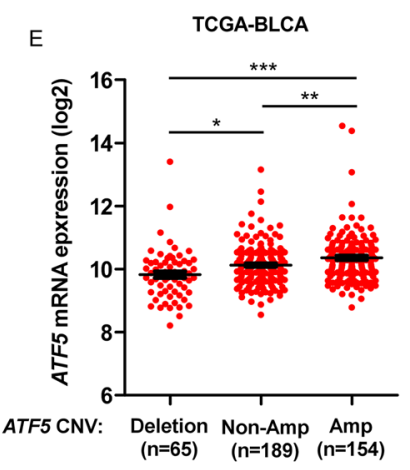

$\mathrm{H}$

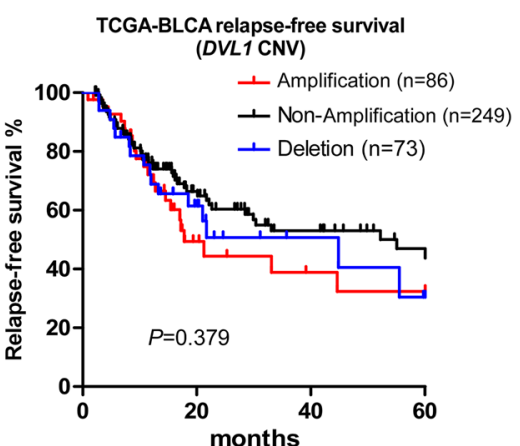

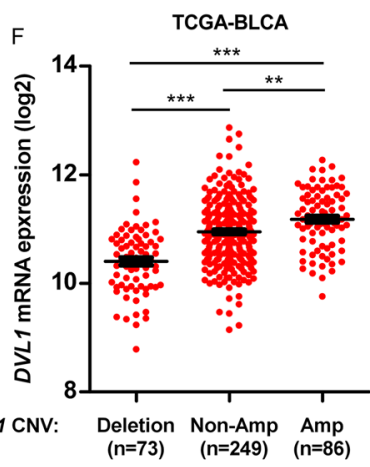

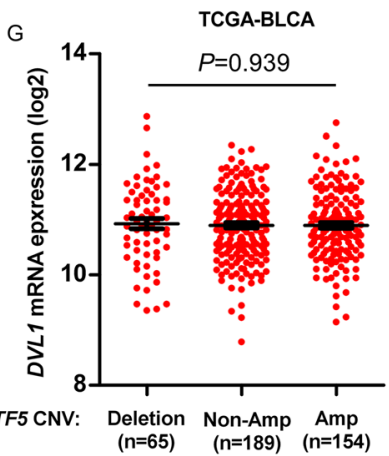

I

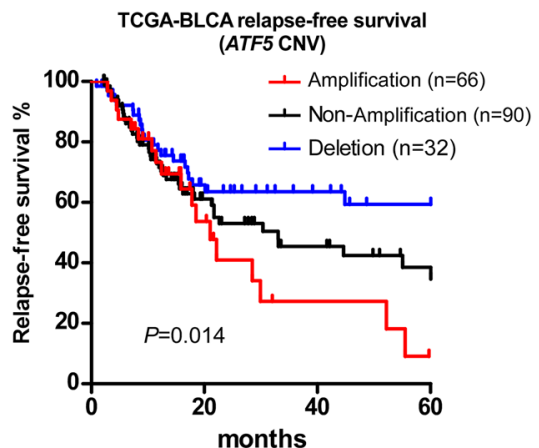

Fig. 6 Aberrant ATF5 amplification contributes to ATF5 overexpression in bladder cancer, which confers poor prognosis. A, B Analyses of ATF5 and DVL1 copy number variant (CNV) in bladder cancer patients from TCGA-BLCA data sets. C, D ATF5, DVL1 gene CNV and corresponding mRNA expression in bladder cancer patients from TCGA-BLCA data sets. E, F ATF5, DLV1 gene CNV and corresponding mRNA expression in a TCGA bladder cancer data set $(P<0.05)$. G ATF5 gene CNV and corresponding DVL1 gene expression in a TCGA bladder cancer data set $(P=0.939)$. $\mathbf{H}$ Kaplan-Meier analysis of relapse-free survival for patients with amplified, non-amplified or deletion of DVL1 expression $(P=0.379)$. I Kaplan-Meier analysis of relapse-free survival for patients with amplified, non-amplified or deletion of ATF5 expression $(P=0.014)$. ${ }^{*} P<0.05,{ }^{* *} P<0.01,{ }^{* * *} P<0.001$. TCGA, the cancer genome atlas; BLCA, bladder urothelial carcinoma; CNV, copy number variant; Amp, amplification 
transcriptional regulatory network in embryonic stem cells [30]. They were commonly used as the markers of CSC in multiple cancers [31,32], including bladder cancer $[33,34]$. Our results indicated that ATF5 up-regulation could promote the stemness of bladder cancer cells. Furthermore, we found that overexpressions of ATF5 in bladder cancer cells promoted the formation of tumor sphere, which was correlated with the relapse-free survival of BLCA patients. On the contrary, the down-regulation of ATF5 inhibited the formation of spheres, which was correlated with the improvement of survival rate. These results indicate that ATF5 overexpression increases tumorigenicity and enhances the TIC-like phenotype in bladder cancer cells, thereby providing hope for developing novel therapeutic strategy to prevent BLCA recurrence.

The Wnt/ $\beta$-catenin signaling, known as the canonical Wnt pathway, is essential for development of the embryo as well as tissue self-renewal of tissues [35, 36]. Abnormal activations of this pathway can lead to unrestrained cells proliferation and malignant transformation [35, 36]. As one of the most relevant pathways associated with TICs, this pathway is often abnormally stimulated in various cancers, including bladder cancer [13, 37]. Stimulation of Wnt/ $\beta$-catenin pathway by miR-543-3p could increase [38], whereas inhibition of this signaling by miR-139-5p may inhibit [39] TIC-like phenotype of BLCA cells, supporting the vital roles of $\mathrm{Wnt} / \beta$-catenin pathway in regulating TIC-like phenotype of bladder cancer. Consistent with these studies, we detected that $\mathrm{Wnt} / \beta$-catenin signaling was abnormally activated in BLCA. We showed that ATF5 could directly target and positively regulate $D V L 1$, leading to the stimulation of Wnt/ $\beta$-catenin signaling.

DVL1, as a main component of the Wnt pathway, takes part in transduction of Wnt signals to $\beta$-catenin, and then stimulates downstream effector factors [40]. In this study, we found that ATF5 could directly bind to DVL1 promoter and stimulate its expression, and then activate the downstream genes of the $\mathrm{Wnt} / \beta$-catenin pathway, including active $\beta$-catenin, MYC, CD44, JUN as well as CCND1, whereas down-regulating ATF5 reduced the expression of DVL1 and these factors. These findings demonstrate a novel mechanism underpinning hyperactivation of the $\mathrm{W} n \mathrm{n} / \beta$-catenin pathway in BLCA. Herein, this study indicates that ATF5 could simulate the Wnt/ $\beta$-catenin pathway and promote tumorigenic capability.

\section{Conclusion}

The present study reveals that overexpression of ATF5 in BLCA directly promotes DVL1 expression and stimulates the $\mathrm{Wnt} / \beta$-catenin signaling, therefore increasing tumorigenicity, enhancing a TIC-like phenotype as well as predicting poor survival. Evaluation of the role of ATF5 in BLCA will broaden our understanding of the mechanism underpinning the high recurrence rate of BLCA, and establish whether ATF5 serves as a prognosis marker or potential treatment target for BLCA recurrence.

\begin{abstract}
Acknowledgements
Not applicable.

Authors' contributions

$L C D$ and ZT designed the study. ZJH, TH and ZX carried out the experiments of cytobiology. XZY, CTY and YHY conducted the follow-up study. CQ, YJK and ZQZ participated in acquisition of data. XKY, WHY and CMK took part in collection of clinical samples. GWB, XM and BJM analyzed the experimental data. ZJH drafted the manuscript. YC, DHF and HZP participated in the revising of the manuscript. All authors read and approved the final manuscript.
\end{abstract}

\section{Funding}

This work was supported by National Natural Science Foundation of China (No. 81902991), Guangzhou Science and Technology Planning Project (No. 202102021056) and Youth Project of The Third Affiliated Hospital of Southern Medical University (No. QD2019N010).

Availability of data and materials

The public datasets of BLCA in NCBI (https://www.ncbi.nlm.nih.gov/gene/); gene set enrichment analysis software program (GSEA, http://software.broad institute.org/gsea/msigdb/index.jsp).

\section{Declarations}

\section{Ethics approval and consent to participate}

This study involved in human specimens was approved by the Clinical Trials Ethics Committee (The Third Affiliated Hospital of Southern Medical University, and Affiliated Cancer Hospital \& Institute of Guangzhou Medical University). This study involved in animals was approved by the Ethics Committee of Experimental Animals, Southern Medical University.

\section{Consent for publication}

Not applicable.

\section{Competing interests}

The authors declare that they have no competing interests.

\section{Author details}

${ }^{1}$ Department of Urology, The Third Affiliated Hospital of Southern Medical University, Guangzhou 510630, Guangdong, People's Republic of China. ${ }^{2}$ Department of Urology, The First People's Hospital of Zhaoqing, Zhaoqing 526020, China. ${ }^{3}$ Department of Laboratory Medicine, Affiliated Cancer Hospital \& Institute of Guangzhou Medical University, Guangzhou 510095, Guangdong, People's Republic of China.

Received: 7 September 2021 Accepted: 1 November 2021

Published online: 11 December 2021

\section{References}

1. de Martel C, Georges D, Bray F, Ferlay J, Clifford GM. Global burden of cancer attributable to infections in 2018: a worldwide incidence analysis. Lancet Glob Health. 2020;8(2):e180-90. https://doi.org/10.1016/S2214109X(19)30488-7.

2. Chou R, Selph S, Buckley DI, Fu R, Griffin JC, Grusing S, Gore JL. Intravesical therapy for the treatment of nonmuscle invasive bladder cancer: a systematic review and meta-analysis. J Urol. 2017;197(5):1189-99. https://doi.org/ 10.1016/j.juro.2016.12.090.

3. Batlle E, Clevers H. Cancer stem cells revisited. Nat Med. 2017;23(10):112434. https://doi.org/10.1038/nm.4409.

4. Kurtova AV, Xiao J, Mo Q, Pazhanisamy S, Krasnow R, Lerner SP, Chen F, Roh TT, Lay E, Ho PL, Chan KS. Blocking PGE2-induced tumour repopulation abrogates bladder cancer chemoresistance. Nature. 2015;517(7533):20913. https://doi.org/10.1038/nature14034. 
5. Wang S, Gao D, Chen Y. The potential of organoids in urological cancer research. Nat Rev Urol. 2017;14(7):401-14. https://doi.org/10.1038/nrurol. 2017.65.

6. Visvader JE, Lindeman GJ. Cancer stem cells in solid tumours: accumulating evidence and unresolved questions. Nat Rev Cancer. 2008;8(10):75568. https://doi.org/10.1038/nrc2499.

7. Jordan CT, Guzman ML, Noble M. Cancer stem cells. N Engl J Med. 2006;355(12):1253-61. https://doi.org/10.1056/NEJMra061808.

8. Ohishi T, Koga F, Migita T. Bladder cancer stem-like cells: their origin and therapeutic perspectives. Int J Mol Sci. 2015. https://doi.org/10.3390/ijms1 7010043.

9. Li Y, Lin K, Yang Z, Han N, Quan X, Guo X, Li C. Bladder cancer stem cells: clonal origin and therapeutic perspectives. Oncotarget. 2017;8(39):6666879. https://doi.org/10.18632/oncotarget.19112.

10. Li J, Yu B, Deng P, Cheng Y, Yu Y, Kevork K, Ramadoss S, Ding X, Li X, Wang CY. KDM3 epigenetically controls tumorigenic potentials of human colorectal cancer stem cells through Wnt/beta-catenin signalling. Nat Commun. 2017;8:15146. https://doi.org/10.1038/ncomms15146.

11. van de Wetering $M$, Sancho E, Verweij C, de Lau W, Oving I, Hurlstone A, van der Horn K, Batlle E, Coudreuse D, Haramis AP, Tjon-Pon-Fong M, Moerer $\mathrm{P}$, van den Born M, et al. The beta-catenin/TCF-4 complex imposes a crypt progenitor phenotype on colorectal cancer cells. Cell. 2002;111(2):241-50. https://doi.org/10.1016/s0092-8674(02)01014-0.

12. Shin K, Lee J, Guo N, Kim J, Lim A, Qu L, Mysorekar IU, Beachy PA. Hedgehog/Wnt feedback supports regenerative proliferation of epithelial stem cells in bladder. Nature. 2011;472(7341):110-4. https://doi.org/10.1038/ nature09851.

13. Pierzynski JA, Hildebrandt MA, Kamat AM, Lin J, Ye Y, Dinney CP, Wu X. Genetic variants in the Wnt/beta-catenin signaling pathway as indicators of bladder cancer risk. J Urol. 2015;194(6):1771-6. https://doi.org/10.1016/j. juro.2015.07.032.

14. Li G, Xu Y, Guan D, Liu Z, Liu DX. HSP70 protein promotes survival of C6 and U87 glioma cells by inhibition of ATF5 degradation. J Biol Chem. 2011;286(23):20251-9. https://doi.org/10.1074/jbc.M110.211771.

15. Torres-Peraza JF, Engel T, Martin-Ibanez R, Sanz-Rodriguez A, FernandezFernandez MR, Esgleas M, Canals JM, Henshall DC, Lucas JJ. Protective neuronal induction of ATF5 in endoplasmic reticulum stress induced by status epilepticus. Brain. 2013;136(Pt 4):1161-76. https://doi.org/10.1093/ brain/awt044.

16. Greene LA, Lee HY, Angelastro JM. The transcription factor ATF5: role in neurodevelopment and neural tumors. J Neurochem. 2009;108(1):11-22. https://doi.org/10.1111/j.1471-4159.2008.05749.x.

17. Arias A, Lame MW, Santarelli L, Hen R, Greene LA, Angelastro JM. Regulated ATF5 loss-of-function in adult mice blocks formation and causes regression/eradication of gliomas. Oncogene. 2012;31(6):739-51. https:// doi.org/10.1038/onc.2011.276.

18. Mason JL, Angelastro JM, Ignatova TN, Kukekov VG, Lin G, Greene LA, Goldman JE. ATF5 regulates the proliferation and differentiation of oligodendrocytes. Mol Cell Neurosci. 2005;29(3):372-80. https://doi.org/10.1016/j. men.2005.03.004.

19. Angelastro JM, Mason JL, Ignatova TN, Kukekov VG, Stengren GB, Goldman JE, Greene LA. Downregulation of activating transcription factor 5 is required for differentiation of neural progenitor cells into astrocytes. J Neurosci. 2005;25(15):3889-99. https://doi.org/10.1523/JNEUROSCI.344704.2005.

20. Angelastro JM, Ignatova TN, Kukekov VG, Steindler DA, Stengren GB, Mendelsohn C, Greene LA. Regulated expression of ATF5 is required for the progression of neural progenitor cells to neurons. J Neurosci. 2003;23(11):4590-600.

21. Nakamori D, Takayama K, Nagamoto Y, Mitani S, Sakurai F, Tachibana M, Mizuguchi $\mathrm{H}$. Hepatic maturation of human iPS cell-derived hepatocytelike cells by ATF5, c/EBPalpha, and PROX1 transduction. Biochem Biophys Res Commun. 2016;469(3):424-9. https://doi.org/10.1016/j.bbrc.2015.12. 007.

22. Zhao Y, Zhang YD, Zhang YY, Qian SW, Zhang ZC, Li SF, Guo L, Liu Y, Wen B, Lei QY, Tang QQ, Li X. p300-dependent acetylation of activating transcription factor 5 enhances C/EBPbeta transactivation of C/EBPalpha during 3T3-L1 differentiation. Mol Cell Biol. 2014;34(3):315-24. https://doi.org/10. 1128/MCB.00956-13.

23. Leong DT, Abraham MC, Gupta A, Lim TC, Chew FT, Hutmacher DW. ATF5, a possible regulator of osteogenic differentiation in human adipose-derived stem cells. J Cell Biochem. 2012;113(8):2744-53. https:// doi.org/10.1002/jcb.24150.

24. Chen MK, Zhou JH, Wang P, Ye YL, Liu Y, Zhou JW, Chen ZJ, Yang JK, Liao DY, Liang ZJ, Xie X, Zhou QZ, Xue KY, et al. BMI1 activates P-glycoprotein via transcription repression of miR-3682-3p and enhances chemoresistance of bladder cancer cell. Aging. 2021;13(14):18310-30. https://doi.org/10. 18632/aging.203277.

25. Angelastro JM, Canoll PD, Kuo J, Weicker M, Costa A, Bruce JN, Greene LA. Selective destruction of glioblastoma cells by interference with the activity or expression of ATF5. Oncogene. 2006;25(6):907-16. https://doi.org/ 10.1038/sj.onc.1209116.

26. Rousseau J, Gagne V, Labuda M, Beaubois C, Sinnett D, Laverdiere C, Moghrabi A, Sallan SE, Silverman LB, Neuberg D, Kutok JL, Krajinovic M. ATF5 polymorphisms influence ATF function and response to treatment in children with childhood acute lymphoblastic leukemia. Blood. 2011;118(22):5883-90. https://doi.org/10.1182/blood-2011-05-355560.

27. Monaco SE, Angelastro JM, Szabolcs M, Greene LA. The transcription factor ATF5 is widely expressed in carcinomas, and interference with its function selectively kills neoplastic, but not nontransformed, breast cell lines. Int J Cancer. 2007;120(9):1883-90. https://doi.org/10.1002/ijc.22469.

28. Ishihara S, Yasuda M, Ishizu A, Ishikawa M, Shirato H, Haga H. Activating transcription factor 5 enhances radioresistance and malignancy in cancer cells. Oncotarget. 2015;6(7):4602-14. https://doi.org/10.18632/oncotarget. 2912.

29. Sheng Z, Ma L, Sun JE, Zhu LJ, Green MR. BCR-ABL suppresses autophagy through ATF5-mediated regulation of mTOR transcription. Blood. 2011;118(10):2840-8. https://doi.org/10.1182/blood-2010-12-322537.

30. Yu HB, Kunarso G, Hong FH, Stanton LW. Zfp206, Oct4, and Sox2 are integrated components of a transcriptional regulatory network in embryonic stem cells. J Biol Chem. 2009;284(45):31327-35. https://doi.org/10.1074/ jbc.M109.016162.

31. Takahashi K, Tanabe K, Ohnuki M, Narita M, Ichisaka T, Tomoda K, Yamanaka S. Induction of pluripotent stem cells from adult human fibroblasts by defined factors. Cell. 2007;131(5):861-72. https://doi.org/10.1016/j.cell. 2007.11.019.

32. Kumar SM, Liu S, Lu H, Zhang H, Zhang PJ, Gimotty PA, Guerra M, Guo W, Xu X. Acquired cancer stem cell phenotypes through Oct4-mediated dedifferentiation. Oncogene. 2012;31(47):4898-911. https://doi.org/10. 1038/onc.2011.656

33. Zhu F, Qian W, Zhang H, Liang Y, Wu M, Zhang Y, Zhang X, Gao Q, Li Y. SOX2 is a marker for stem-like tumor cells in bladder cancer. Stem Cell Rep. 2017;9(2):429-37. https://doi.org/10.1016/j.stemcr.2017.07.004.

34. Sedaghat S, Gheytanchi E, Asgari M, Roudi R, Keymoosi H, Madjd Z. Expression of cancer stem cell markers OCT4 and CD133 in transitional cell carcinomas. Appl Immunohistochem Mol Morphol. 2017;25(3):196-202. https://doi.org/10.1097/PAl.0000000000000291.

35. Logan CY, Nusse R. The Wnt signaling pathway in development and disease. Annu Rev Cell Dev Biol. 2004;20:781-810. https://doi.org/10.1146/ annurev.cellbio.20.010403.113126.

36. Clevers $H$, Nusse R. Wnt/beta-catenin signaling and disease. Cell. 2012;149(6):1192-205. https://doi.org/10.1016/j.cell.2012.05.012.

37. Mohammed MK, Shao C, Wang J, Wei Q, Wang X, Collier Z, Tang S, Liu H, Zhang F, Huang J, Guo D, Lu M, Liu F, et al. Wnt/beta-catenin signaling plays an ever-expanding role in stem cell self-renewal, tumorigenesis and cancer chemoresistance. Genes Dis. 2016;3(1):11-40. https://doi.org/10. 1016/j.gendis.2015.12.004.

38. Gao RL, Chen XR, Li YN, Yan XY, Sun JG, He QL, Cai FZ. Upregulation of miR-543-3p promotes growth and stem cell-like phenotype in bladder cancer by activating the Wnt/beta-catenin signaling pathway. Int J Clin Exp Pathol. 2017;10(9):9418-26.

39. Luo H, Yang R, Li C, Tong Y, Fan L, Liu X, Xu C. MicroRNA-139-5p inhibits bladder cancer proliferation and self-renewal by targeting the Bmi1 oncogene. Tumour Biol. 2017;39(7):1393371250. https://doi.org/10.1177/10104 28317718414.

40. Gao C, Chen YG. Dishevelled: the hub of Wnt signaling. Cell Signal. 2010;22(5):717-27. https://doi.org/10.1016/j.cellsig.2009.11.021.

\section{Publisher's Note}

Springer Nature remains neutral with regard to jurisdictional claims in published maps and institutional affiliations. 